\title{
English for Ecotourism and Its Sustainability with Augmented Reality Technology
}

\author{
Chi-ying Chien ${ }^{1}$ \\ ${ }^{1}$ Department of Foreign Languages, Fooyin University, Kaohsiung, Taiwan (R.O.C.) \\ Correspondence: Chi-ying Chien, Department of Foreign Languages, Fooyin University, 151 Jinxue Rd., Daliao \\ Dist., Kaohsiung City 83102, Taiwan (R.O.C.). Tel: 886-091-199-3450. E-mail: en047@fy.edu.tw
}

Received: August 26, 2018

Accepted: March 18, 2019

Online Published: May 29, 2019

doi:10.5539/ies.v12n6p134

URL: https://doi.org/10.5539/ies.v12n6p134

\begin{abstract}
When it comes to traveling, more and more people are becoming interested in having profound experiences to the places they are visiting and the local inhabitants. However, there currently very few tour guides in Taiwan who are well equipped to promote preservation of the environment and sustainable development. In addition, Taiwanese students interested in the field have been found to rarely talk with foreigners about topics related to ecology or environmental protection even though they are popular issues around the world. This study centres on English for ecotourism that is supplemented by comprehensive project-based learning (CPBL) and augmented reality (AR) technology to explore how teaching such a course using AR technology impacts English for specific purposes (ESP) learning and sustainable development. Two classes of ninety-nine college students in total participated in the study. The research also involved a survey, comprised of three sets of questionnaires concerning student satisfaction with AR application, CPBL, and ESP learning. An independent t-test and an analysis of variance were completed to examine the variables of gender, class, and English proficiency level to understand the significance of student satisfaction. The results found that more tourists chose the AR versions of the brochures than the general versions. Satisfaction between both foreign language classes regarding CPBL and ESP learning was significant. Across the three different English proficiency levels, the mean level of student satisfaction for all three variables was highest in the high proficiency group. This study reveals that adopting an AR approach for CPBL and ESP learning could better achieve the goals of ESP teaching and sustainable development than the traditional English teaching model based on in-class lectures.
\end{abstract}

Keywords: augmented reality, technology-enhanced learning, English for specific purposes, comprehensive project-based learning, ecotourism

\section{Introduction}

On the weekends, many people choose to travel to tourist spots, but their visits can bring a heavy load on nature. Such individuals used to join these tours to have some fun, taste the local food, and buy some souvenirs. Then they would leave the area happy to have taken some pictures of their adventures. Traveling to them was about experiencing a change in location without taking the time to understand the local community, its customs, and the natural landscape. But now times have changed, and more and more people are interested in experiencing travel that yields profound experiences where they can show their empathy to the local environment and its people by promoting sustainable development. However, even though there are many tour guides in Taiwan, few of them are well equipped to share knowledge about and support sustainable development - and even fewer of these individuals can give ecotours in English.

Looking at most educational books or textbooks teaching English for tourism, general topics include pre-departure preparations concerning buying tickets and booking hotels, airport check-in procedures, shopping and tax refund information, potential security and boarding problems for airplanes, potential transfer and luggage problems, currency exchange and local transportation information upon arrival, ideas for eating out and local entertainment or sightseeing, souvenir suggestions, and potential problems with getting sick or experiencing an emergency situation while abroad (Chang, 2015; Cheng, 2018; Live ABC, 2014). The majority of these books follow a similar teaching structure that features example dialogue; uses common sentence patterns, vocabulary, and phrases; and includes a list of common expressions and their usage. Moreover, most lessens in such material end with a few exercises and a short assessment. 
Due to the growing importance of ecology and environmental protection in tourism, it is believed that while teaching English for tourism, topics such as ecology education and environmental protection should also be taken into account. Extra English training for specialised knowledge is a necessity. To make serious issues more approachable, provide more flexibility in expression, and transform ecological issues into more engaging topics, augmented reality (AR) technology can be applied to capture people's attention and lighten the mood, thereby strengthening listener awareness and better communicating any take-home messages. To advance English for specific purposes (ESP) teaching and learning, this study focuses on English for tourism with regard to ecological conservation and environmental education and takes a comprehensive project-based learning (CPBL) and AR technology approach to investigate how teaching English for ecotourism with the application of AR technology impacts ESP learning and sustainable development.

\section{Literature Review}

In view of the fact that most people including tour guides do not understand the true essence of ecotourism, the definition of tourism and related information will be explained and clarified. Since this study is about teaching English for ecotourism, ESP teaching strategies will be described and the pedagogy used in this study will be further discussed. Moreover, many schools today have added AR technology to enhance student learning, a practice that has also been included and discussed in the study.

\subsection{Definition of the Terms}

According to the Oxford English Dictionary, the word ecotour was first recorded in 1973, and ecotourism was probably used later in 1982. Ecotourism is a compound of the prefix eco- and the word tourism. It is a neologism and an activity invented in the late 20th century. The following are two definitions for the word:

Ecotourism is a noun describing "tourism to areas of ecological interest (typically exotic and often threatened natural environments), esp. to support conservation efforts and observe wildlife; spec. access to an endangered environment controlled so as to have the least possible adverse effect" (The New Oxford Dictionary of English, 1998). At its core, ecotourism is "nature based, environmentally educated, and sustainably managed" (Weaver, 2001).

According to the Internet resource The International Ecotourism Society, a non-profit association, ecotourism is the activity of visiting fragile, pristine, and undisturbed natural areas while having a low impact on them. It is usually a small-scale alternative compared to standard commercial tourism. In fact, it has been defended as "responsible travel to conserve the environment, sustains the well-being of the local people, and involves interpretation and education" (The Definition made in 2015)

Regarding whether a specific travel itinerary can be recognised as an ecotourism tour, a white paper published by Taiwan's government in 2005 defines ecotourism as a form of tourism in a natural area that emphasises the concept of ecological conservation and the ultimate goal of sustainable development. Even if a tour takes place in a natural area, its operations still need to be considered to judge whether the tour design does emphasise the concept of ecological conservation and the goal of sustainable development. For example, if a local businessman (such as a tour guide) does not return part of his income to the community to support shared services, a travel agency provides tourists with bottled water or single-use plasticware, an indigenous person brings tourists into the mountains to hunt and cook wildlife for food, transportation tools bring in air pollution and waste, a tourist catches small wildlife or collects plants or fruit to bring home as a souvenir or alternatively mistreats wild animals (e.g., by shining a flashlight at a frog's sensitive eyes), then actions against the principles of ecotourism are occurring. Any of these activities are considered bad news for ecotourism.

\subsection{English for Specific Purposes Teaching Methods}

\subsubsection{General Teaching Methods in English for Specific Purposes}

Robinson (1991) argues that there is little difference between ESP and English language teaching (ELT) teaching methods. Speaking strictly on methodology, it is hard to say whether ELT copies creativity from ESP or ESP borrows ideas from ELT. However, Dudley-Evans and St. John (1998) define clear methodological principles for ESP. They believe the usage of methodology should reflect the disciplines or professions to which the language being taught needs to relate and that these factors will generate quite different classroom interactions and teaching methodologies than general English learning. Looking at the term specific purposes highlights precisely how ESP teaching materials focus on topics and activities for a well-defined reason, and thus in many situations, a certain methodology for a given subject or professional area should be explored (Widdowson, 1983).

We have to make sure that we are familiar with the underlying methodologies of different disciplines and professions because whenever ESP learners take advantage of the methods used in their educational research or 
professional work, these methods benefit them and make ESP learning more effective. For example, in learning business activities in a work setting, people take advantage of the problem-solving methods commonly used in that business field, such as the case study approach or Big Data analyses (Dudley-Evans \& St. John, 1998). If learners are studying or working in the engineering field, then the problem-solving methodology should be applied to increase practical discussions and the conducting of the ESP classes (Dudley-Evans, 1998). Therefore, ESP instructors have to make flexible and proper adjustments in their teaching strategies according to the nature of the different disciplines and the needs of the students.

\subsubsection{Teaching English for Ecotourism and CPBL}

English for tourism is the type of English that is found in most beginning- and intermediate-level textbooks on English as a second language, and the English materials used are typically meant to provide students with working knowledge of the language so that they can read basic English, comprehend it when they hear it, and speak intelligible sentences to foreign tourists within a short period of training.

In the tourism market, there are numerous tour guides who accompany foreigners traveling in Taiwan, but only a few of them are well equipped with knowledge of ecological conservation, environmental protection, landscape maintenance, and cultural heritage as well as practical experience; and an even more select population are capable of introducing local wildlife, ecology, and landscapes in English. Take bird-watching in Taiwan as an example. Taiwan's bird species are famous internationally, but there are no more than ten professional tour guides who can show foreign tourists around and provide information in English and Japanese (Lee, Choi, \& Park, 2009). Although Taiwan has no magnificent mountains or huge waterfalls, there are also exquisite and diverse geological and landscape views that may attract foreigners to the island; however, no tour guides with expertise in ecology can be found. Whale- or dolphin-watching and water-diving excursions run into the same problems. The island is well known for its abundant marine resources, but the insufficient number of English speakers is the main reason why Taiwan has long been unable to develop its marine ecotourism internationally.

If the government wants to attract foreigners and grow ecotourism, cultivating English tour guides with the ability to arrange ecotours is a must. Moreover, if ecotourism efforts do not include preparing people to provide professional explanations and environmental education, then the government will have failed to fulfil a key component of ecotourism. In addition, sometimes simple misunderstandings and ill-advised actions can even lead to more damage to the environment and the communication of misinformation to tourists. Instructors of English for ecotourism need to be careful and considerate when developing and teaching curricula on ecotourism.

Thus, courses focused on English for ecotourism should feature task-based teaching and learning with the aim of preparing individuals to provide professional explanations, environmental education, and proper operational protocols. CPBL is a task-based teaching method and also an exciting alternative to traditional classroom learning. It offers challenges and questions for students to explore so that they can acquire deeper knowledge through active teaching design.

CPBL usually starts with examining what students already know and what they need to know. Within a given group, developing proper communication skills is essential for teamwork to run smoothly. During the learning process, critical thinking, problem-solving, collaboration, and various forms of communication, the so-called 21 st-century skills (Fadel, 2008) are cultivated to produce the final outcome. In addition, students are inspired by an open-ended driving question and embrace the challenge of stating and defending their positions with available evidence while also remaining flexible enough to maintain healthy interactions and foster new ideas. After numerous discussions and productive arguments, students are able to create something new and voice what they think of their choices. Then the students publicly present their products or performance. Finally, the students acquire feedback from the instructor, their peers, and any other participants and are given the opportunity to do a self-reflection on their work in the hope of cementing lessons learned for the future.

\subsection{Application of Augmented Reality in Education}

For ESP classes, there is not much talk about using technology. Most ESP curriculum design is related to teaching strategies on reading, writing, and communication to meet occupational goals and needs. However, instructors who use technology will find that it supports learning well and fills the gaps in support left by traditional types of language learning. Furthermore, integrating technology is popular among most students. It helps create new forms of communication and visual modes of discourse during group work. With today's technological developments, students can now synchronously or asynchronously work together and their individual contributions can easily be published, displayed, and shared with others.

$\mathrm{AR}$ is one example of a technology that serves various purposes in the classroom. Zhou, Duh, and Billinghurst 
(Zhou, Duh, \& Billinghurst, 2008; Billinghurst, 2009) describe AR as any technology that allows a computer to generate virtual imagery and accurately overlay physical objects in real time. With AR, it is possible to engage students with learning materials in three-dimensional overlays. According to Burns (2016), this exciting technology has put virtual content at the top of the real world and provided students with an opportunity to interact with content in new ways. The idea of augmented reality (AR) is more than just a gimmick. We admit that AR does attract the attention of the students, but we also want to ensure that it supports meaningful learning activities. Deeper learning and multiple learning environments can undoubtedly move beyond the "gotcha factor."

In terms of skills training, project-based learning may also play an important role by integrating knowledge acquisition with AR. The application of AR to learn professional English can render ESP teaching and learning more visible and effective. With the example of learning English for ecotourism, the virtual objects and uploaded videos can help students simulate the description of an itinerary in English and also illustrate ecological knowledge during a sightseeing tour through the AR system. This will not only help users experience the scene's ambiance but also enhance the pleasure experienced with interactions carried out in professional English.

\section{Method}

\subsection{Purpose of the Research}

The main purpose of this study is to investigate whether teaching English for ecotourism by supplementing the teaching strategy with CPBL and AR technology strengthens ESP learning and promotes sustainable development.

\subsection{Augmented Reality Building and Brochures}

AR technology was used to create little AR masters to interpret the landscape and ecology. These AR masters can easily direct people's attention towards ecological conservation through AR support features and their interactions with people. The students were tasked with designing brochures aimed at supporting the use of AR and providing ecological explanations to tourists, and each of the brochures had to include pictures, videos with captions, and two little AR masters. One little AR master was assigned to report on ecological issues in the videos that were shot with English audio only and then subtitled in both Chinese and English; the other little AR master could ask ecological questions and interact with people by giving them answers when they tapped the trigger in the AR software. There is no doubt that the questions the students made were all related to issues they found to be important when they investigated and observed the wetland parks. The AR building was done by following the steps described in the rest of this section.

In the first phase, a map was created in the brochure and the target icons (which are the markers) were prepared and placed on the map. These icons were then labelled with numbers (Figures $1 \& 2$ ). Then images were chosen for the two little AR masters. Next the introduction videos were put together with audio recordings in English only and subtitling in both Chinese and English. Finally, the students inserted inquiries in the audio and the captions.

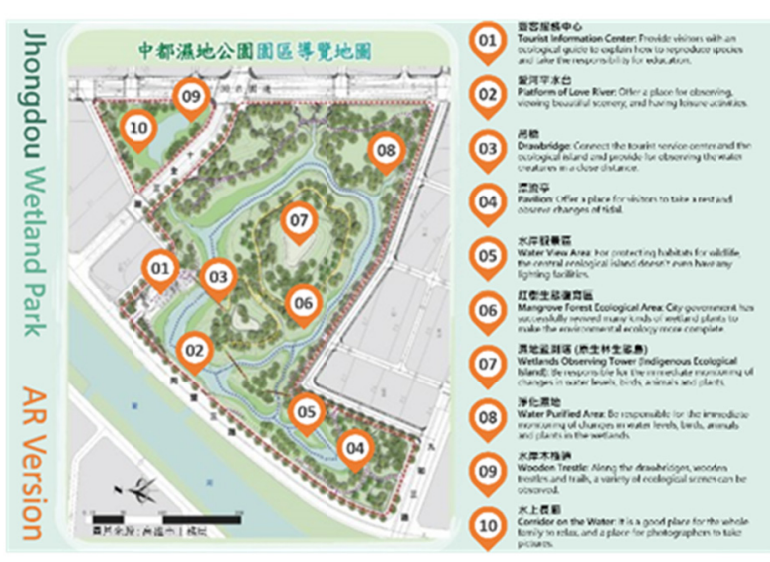

Figure 1. An AR version of the brochure
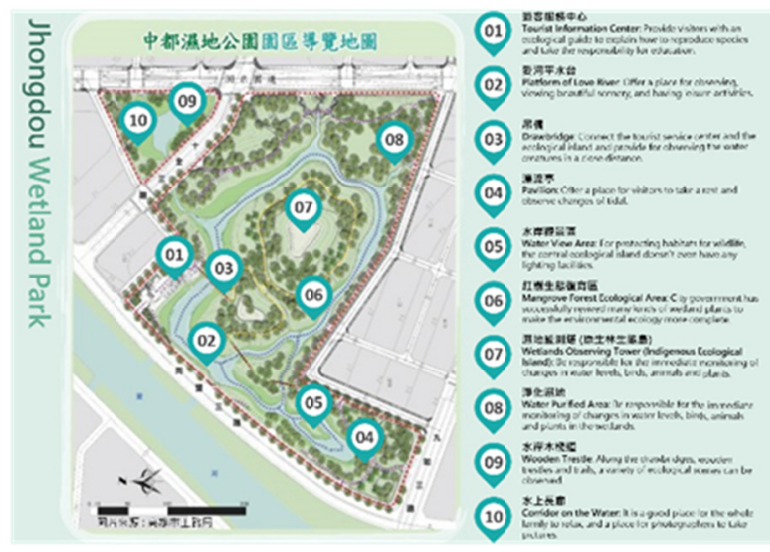

Figure 2. A general version of the brochure

In the second phase, students upload maps into the HP Reveal 6.0.0 software (formerly known as Aurasma), and then they masked the target icon, as seen with icon 02 on the map in Figure 3. After that, the students uploaded the image of little AR master 1 (Note 1) to HP Reveal and added their introduction videos to the program as well. 
Then it was time to upload the image of little AR master 2 (Note 2) to HP Reveal and also add any relevant pictures with answers (Figure 4). Finally, the students spent time adjusting the positions and angles of the videos and little AR masters as needed (Figure 5).

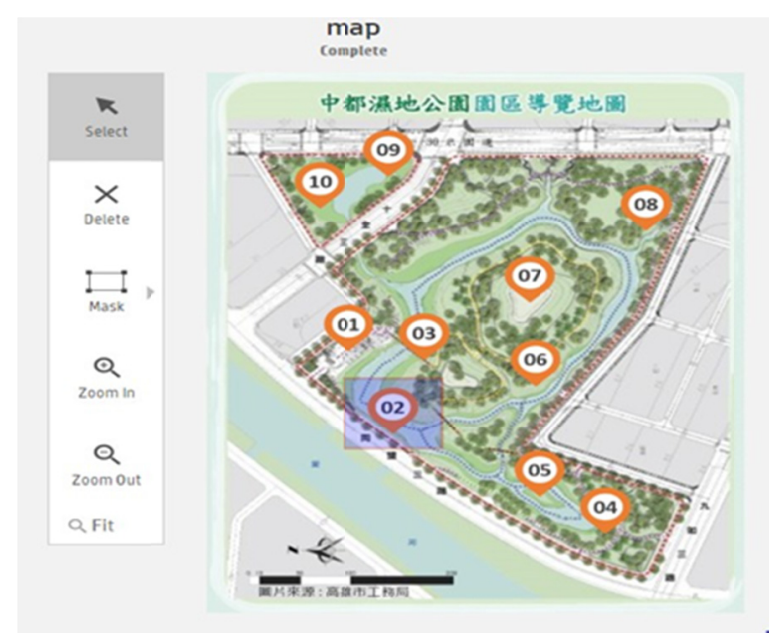

Figures 3. Choosing and masking the target icon

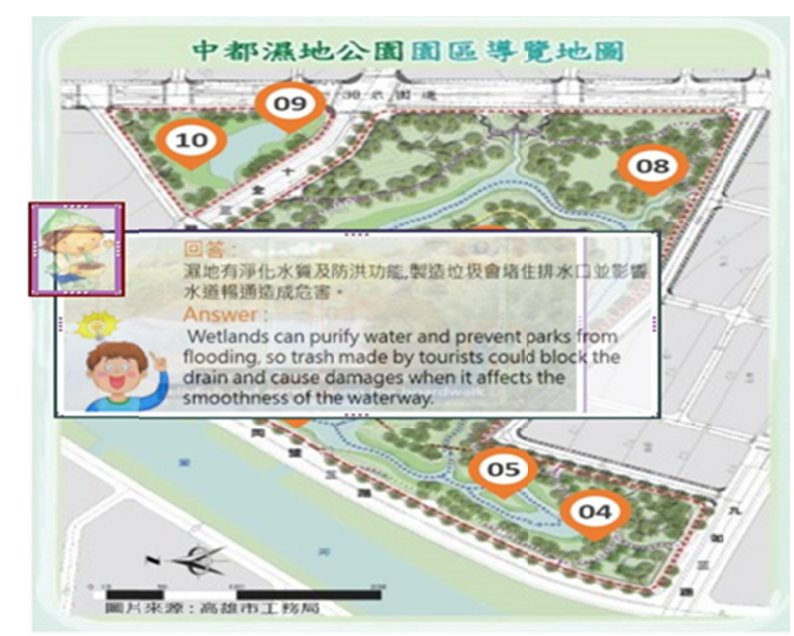

Figure 4. Uploading relevant material
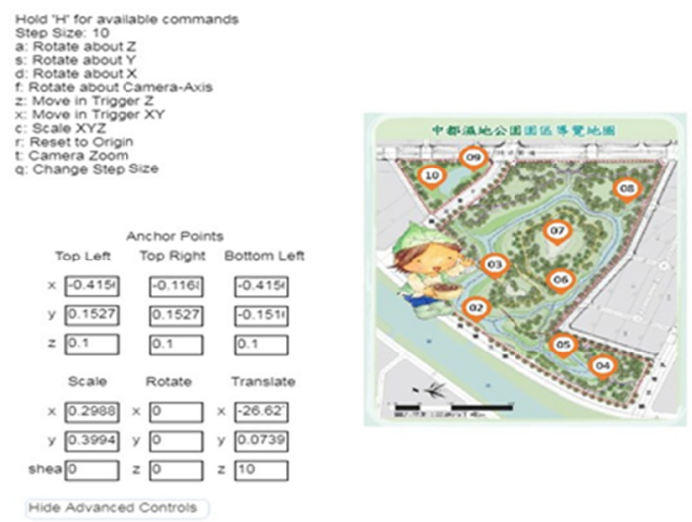

Figure 5. Adjusting the positions and angles of videos and images

In the third phase, edit actions were carried out to assign commands for the uploaded videos and images (Figure 6). The images can only be triggered when the HP Reveal camera detects the marker and shows people the two little AR masters in response (Figure 7). When a user double taps little AR master 1 on a smartphone, the introduction videos play (Figure 8). When a user taps little AR master 2, the user can get the answers to the questions shown on the last page of the brochure (Figure 9). Finally, users can enjoy the student-produced AR effects by using the HP Reveal camera to go through an ecotourism introduction. 


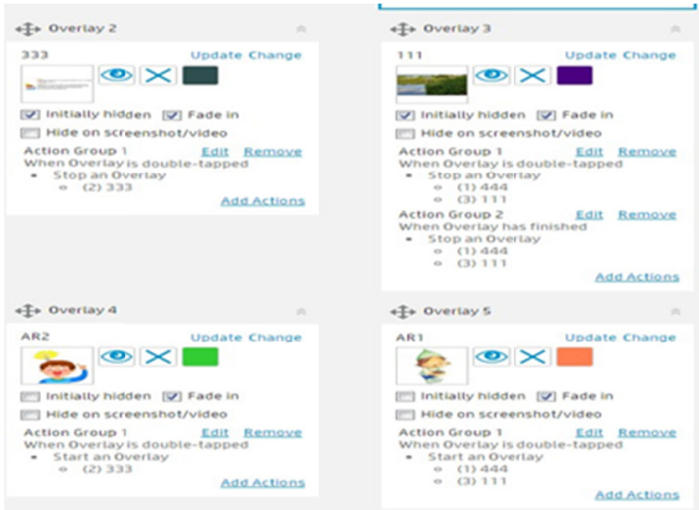

Figure 6. Editing the actions for the videos and images

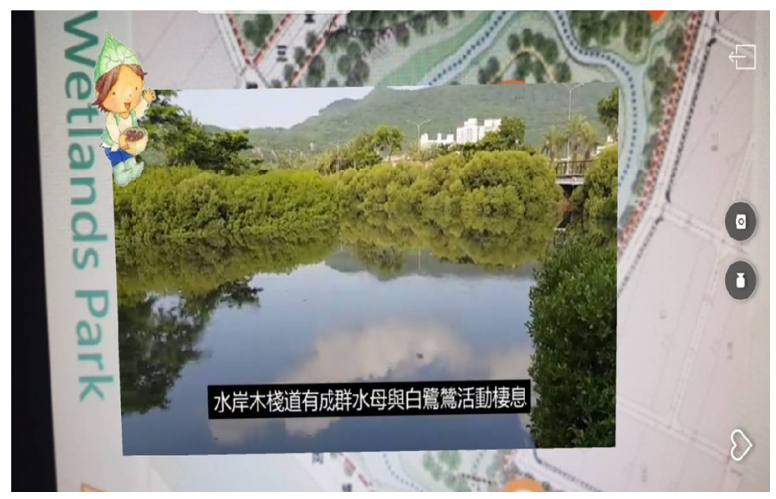

Figure 8 . The audio-visual content triggered with the first litter AR master

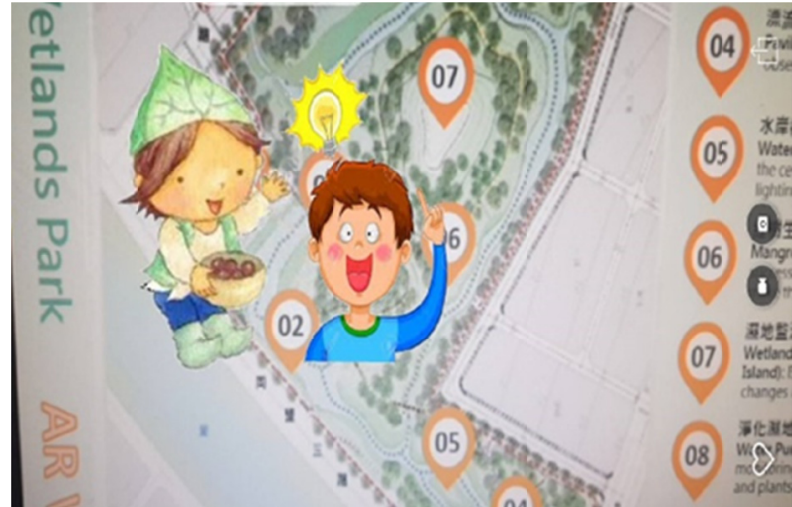

Figure 7. Two little AR masters are consistently detected on the marker

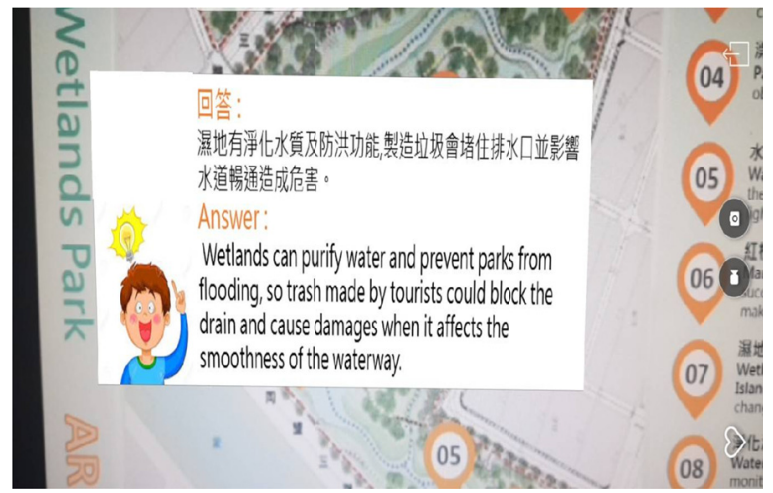

Figure 9. The answer triggered with the second little AR master

Although the videos were made to support Chinese-English translation, they featured English audio only. (However, Chinese captions were available for those who do not understand English.) Any audio-visual content appeared above the images, and then the interactive AR features naturally occurred. Each group prepared a general version of the brochure (Figure 1) and an AR version (Figure 2). The two little AR masters on the brochures can guide users through what they can see, learn, and be aware of when traveling through a wetland wildlife refuge.

\subsection{Data Collection}

\subsubsection{Evaluating the Wetland Park Environments}

This study focuses on teaching English for ecotourism, so Taiwan's wetland parks were chosen as the main topics for the project. The learning and content design processes that the students followed are displayed in Figure 10.

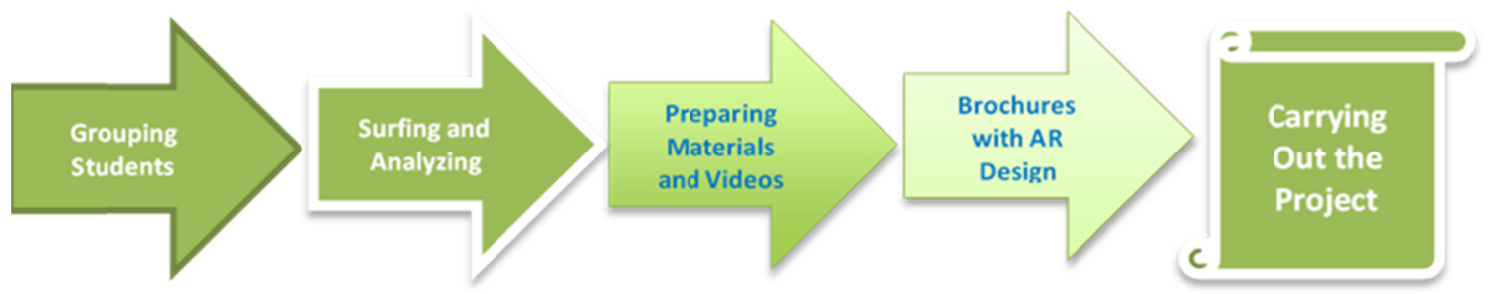

Figure 10. Flow chart covering the brochure project's basic design

To understand and evaluate whether tourism in wetland parks met the requirements of ecotourism, students were divided into groups to investigate ten wetland wildlife refuges in Southern Taiwan. Each group was assigned to a 
specific wetland park. The students were asked to research their wetland parks at libraries and to visit the parks' official websites to determine what useful and important messages could be shared through the project. Then the students looked into wetland ecotourism. Any collected information was evaluated according to the ecotourism standards to see whether the wetland ecotourism promoted in this study met the requirements of ecological conservation, environmental protection, community charity, sustainable development, and environmental education. A checklist for an ecotourism itinerary was adopted and revised according to the form found on the official webpage of the Evacuative Information System, Tourism Bureau (Checking form for ecotourism itinerary), for students to evaluate and consider the essential elements of ecotourism. The students also had to visit their parks in person several times to take pictures and film short videos to put together content and information for the project. The results of their investigations split across the ten groups are reported in the findings and discussion section.

\subsubsection{The Design for Comprehensive Project-Based Learning}

Figure 11 shows how the CPBL project was carried out with both versions of the brochures. One guiding question for CPBL was set in advance: How can sustainable development in ecotourism be maintained? Each group was asked to prepare two versions of the brochure. One was called the general version and had a Chinese/English text introduction only, and the other one was called the AR version and had an introduction supported with an AR design.

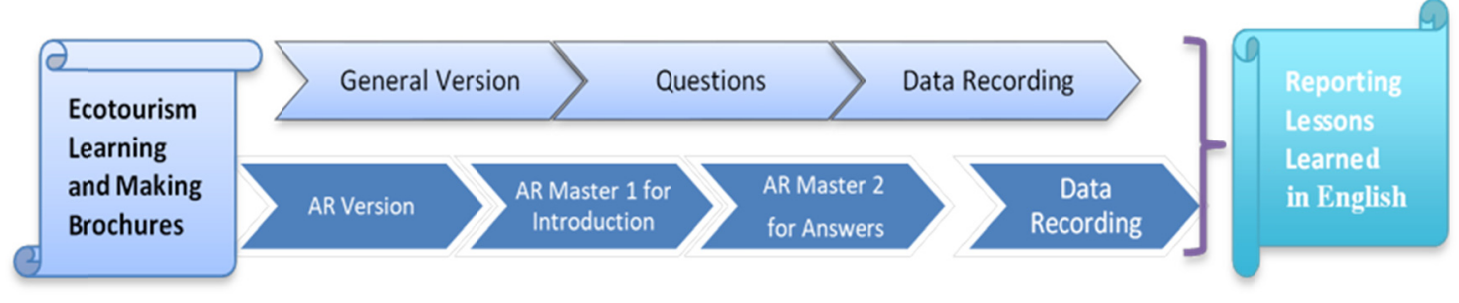

Figure 11. Flow chart for comprehensive project-based learning

The ninety-nine participants were students from the Department of Foreign Languages, which was divided into junior college program (five-year program) and college program (four-year program). The students were divided into ten groups that were assigned to ten wetland parks. Each group had nine to ten students who were then further divided to visit five locations in a given park to provide Chinese/English guidance. Data collection took place over a period of about a month. The general version of the brochure was created for tourists to pick up themselves, and after they read it, the students would ask them questions for the interaction component. The AR version was designed with the intention of the students showing tourists how to use their smartphones to acquire basic knowledge about the park by double tapping little AR master 1 to watch the introduction videos. Then the students would ask a tourist one question about ecotourism in Chinese or English. (The questions were also printed on the back of the brochures). After that, the tourists were asked to double tap little AR master 2 to get the answers. All the students recorded basic information about the tourists and the number of correct answers found during their interactions. These results are reported in the findings and discussion section.

\subsubsection{Survey of Satisfaction}

The purpose of the satisfaction survey was to test the significance of AR application, CPBL, and ESP learning according to three variables: gender, class, and English proficiency. English scores were collected for three written tests on ecotourism articles given after related lectures. The data were then divided into three groups before examination: the high proficiency group (scores of 55-84.5), the intermediate group (scores of 43-54.5), and the low proficiency group (scores of 18-42.4). There were thirty-three students in each group.

This research involved a survey comprised of three sets of questionnaires concerning student satisfaction with AR application, CPBL, and ESP learning. The first questionnaire was about AR application and had six statements that were coded AR1 to AR6. The second questionnaire addressed CPBL and had five statements coded PB1 to PB5, and the last questionnaire focused on ESP learning and had six statements coded ESP1 to ESP6. The AR questionnaire was adapted from the evaluation framework for an immersive virtual environment developed by Roussos et al. (1999) with the VR-assisted environment being replaced with AR. The CPBL questionnaire was based on Hye-Jung and Cheolil's study (Lee \& Lim, 2012) examining the effectiveness of peer evaluation with 
blended team project-based learning. The ESP questionnaire was developed by the researcher to cover questions on learning about ecotourism and using AR for support. Data collected through the questionnaires were analysed and interpreted using the IBM SPSS 22.0 statistical software package to detect significant differences for the variables of gender, class, and English proficiency level.

\subsection{Data Analysis}

The analysis of data for the variables of gender and class was carried out using an independent sample $t$-test to compare the means of the two independent groups and determine whether statistical evidence shows that the satisfaction levels of different genders or classes were significantly different. If the results reached significance, then the $t$-test was performed again to figure out which statements were significant, meaning most students felt a high level of satisfaction towards the item. Besides the survey on student satisfaction towards AR application and CPBL, ESP learning was examined using an analysis of variance to test the three groups of English proficiency levels (the factors) and determine whether there was a difference among them. If the test reached significance, post hoc tests were adopted to further explore which groups had bigger differences and which statements acquired a high level of recognition from the majority of students.

\section{Results}

\subsection{Findings for Validity and Reliability}

Cronbach's alpha coefficient was adopted in this study to examine reliability. The Cronbach's alpha coefficient (r) was found to be 0.87 in the general reliability analysis of the questionnaires: Cronbach's alpha coefficient was 0.71 for satisfaction with AR application, 0.63 for satisfaction with CPBL, and 0.72 for satisfaction with ESP learning. The statistical results indicate a high level of correlation (consistency) for the survey.

Factor analysis was conducted to test the validity of the satisfaction survey with regard to AR application, CPBL, and ESP learning. The adequacy of the sample size was assessed using the Kaiser-Meyer-Olkin test and yielded a value of 0.854 . The Barlett sphericity test was conducted to examine normal distributions for the variables, and the result of significance reached .000 . After factor analysis was carried out, eigenvalues greater than one were identified as five dimensions, and the five dimensions accounted for $62.527 \%$ of the total variance.

\subsection{Independent Sample t-Test for Satisfaction between Different Genders and Classes}

In terms of the satisfaction survey, the AR questionnaire adopted statements from Roussos et al. (1999), which included the following considerations: (1) AR1 look at usability in terms of learning an interface, comprehending instructions, and physical and emotional comfort (the technical aspect). (2) AR2 focused on adaptability and centred on becoming immersed and comfortable in the environment (the orientation aspect). (3) AR3 was about patience, which meant the length of time students were engaged, the amount of time that passed before they reached fatigue, and their reported and perceived levels of enjoyment (the affective aspect). (4) AR4 covered conceptual change, meaning student performance within and outside the environment, stimulated recall techniques, and the students' skills with recording videos (the cognitive aspect). (5) AR5 was about teaching techniques, including turn-taking abilities, conflict-resolution skills, and social and comparison techniques (the pedagogical aspect). (6) AR6 on effectiveness explored comparisons of the learning results inside and outside of $\mathrm{AR}$ environments (the collaborative AR aspect). The rest of the statements featured on the questionnaires for CPBL and ESP learning are shown in subsequent tables because of the significance levels.

Tables 1 and 2 show that satisfaction with AR application did not reach significance between different genders and classes. However, the mean in the foreign language class 2 (mean $=3.6920)$ is lower than the mean of the class 1 $($ mean $=3.8239)$, and its standard deviation $(\mathrm{SD}=0.4212)$ is just half of the foreign language class's $(\mathrm{SD}=$ 0.8876). This suggests that the satisfaction survey in the foreign language group resulted in many more different opinions towards AR design and the brochure project in comparison to the tourism group. From the findings of in-class observation, the AR design process was more or less connected to a student's former computer skills. Many students complained that they were unfamiliar with the software's operations, and they accumulated a lot of negative emotions and failures while working on the project. This was especially true for students in the foreign language department. As mentioned in the methodology section, some students selected beautiful scenic pictures or vague images for their AR markers that were too complicated to trigger the augmented videos or pictures as they wished. In addition, many students needed help with language corrections for their Chinese captions and English translations. Spending time on English proofreading helped to ensure the quality of the AR brochures. To sum up, although there were undeniable advantages to using AR since it allowed visitors to easily connect ecological concepts with maps of the wetland parks, the students faced numerous challenges with the application of AR technology. 
The main problem was that the process of creating AR effects was very complex, and the technology and skills needed for successful AR application were all brand new to most of the students. However, without a doubt, AR can create better learning effects and experiences than only using videos to supplement lectures.

Table 1. Satisfaction between genders for augmented reality, comprehensive project-based learning, and English for specific purposes $(N=99 ; \mathrm{M}=28, \mathrm{~F}=71)$

\begin{tabular}{ccccccc}
\hline & Gender & Mean & SD & $F$ & $t$ & $p$-value \\
\hline AR & 1 & 3.7083 & .55486 & 2.186 & -.476 & .635 \\
& 2 & 3.7840 & .76449 & & & \\
PB & 1 & 3.6000 & .68204 & .607 & -.550 & .584 \\
& 2 & 3.6901 & .75350 & & & \\
ESP & 1 & 3.7202 & .52126 & 7.271 & -.185 & .854 \\
& 2 & 3.7488 & .74954 & & & \\
\hline
\end{tabular}

Table 2. Satisfaction between two classes for augmented reality, comprehensive project-based learning, and English for specific purposes

\begin{tabular}{ccccccc}
\hline & Class & Mean & SD & $F$ & $t$ & $p$-value \\
\hline AR & $1^{\mathrm{a}}$ & 3.8239 & .88760 & 24.670 & .922 & .359 \\
& $2^{\mathrm{b}}$ & 3.6920 & .42012 & & & \\
$\mathrm{~PB}$ & 1 & 3.8377 & .81151 & 6.099 & 2.600 & $.011^{*}$ \\
& 2 & 3.4652 & .57357 & & & \\
$\mathrm{ESP}$ & 1 & 3.8805 & .78199 & 11.309 & 2.205 & $.030^{*}$ \\
& 2 & 3.5797 & .53024 & & & \\
\hline
\end{tabular}

$* p<.05 ;{ }^{\mathrm{a}} 1=$ Foreign language class $1(N=53) ;{ }^{\mathrm{b}} 2=$ Foreign language class $2(N=46)$.

Table 2 shows the results of the independent $t$-test. The values for $\operatorname{PB}(t=0.011, p<.05)$ and $\operatorname{ESP}(t=0.03, p<.05)$ all proved to be significant. However, student satisfaction towards the two variables between the different classes varied. Therefore, post-tests were conducted to assess all the statements related to PB and ESP relatively in a $t$-test in order to figure out which statement had significant differences between the two classes.

Meanwhile, Table 3 indicates that a high level of significance for CPBL was achieved with statement PB5 ( $t=$ $0.002, p<.05$ ), which means that student satisfaction towards the quality of the work performed in the foreign language class 1 was higher than the level of satisfaction experienced by the students in the class 2 . A post-test was also conducted to assess the ESP learning statements in a $t$-test again, and the testing revealed levels of significance for ESP1 and ESP2 (Table 4), which suggests more students in the foreign language class 1 felt satisfied with how they broadened their cognition on related ecological knowledge and increased their ecological vocabulary than their counterparts in the class 2 .

Table 3. Satisfaction between two classes for comprehensive project-based learning

\begin{tabular}{|c|c|c|c|c|c|c|}
\hline \multirow{2}{*}{\multicolumn{2}{|c|}{ Item (rated on a 5-point Likert scale) }} & \multicolumn{2}{|c|}{ Mean } & \multirow{3}{*}{$\begin{array}{c}F \\
.485\end{array}$} & \multirow{3}{*}{$\frac{t}{1.565}$} & \multirow{3}{*}{$\frac{p \text {-value }}{.121}$} \\
\hline & & \multirow{2}{*}{$\frac{1}{3.91}$} & \multirow{2}{*}{$\frac{2}{3.54}$} & & & \\
\hline PB1 & ${ }^{\mathrm{a}}$ Participated in group project or meetings (Collaboration) & & & & & \\
\hline PB2 & $\begin{array}{l}\text { Helped keep the group focused on the task } \\
\text { (Problem solving and communication) }\end{array}$ & 3.81 & 3.65 & .010 & 0.671 & .504 \\
\hline PB3 & $\begin{array}{l}\text { Contributed useful ideas } \\
\text { (Critical thinking and communication) }\end{array}$ & 3.62 & 3.41 & .93. & 0.855 & .395 \\
\hline PB4 & $\begin{array}{l}\text { Quantity of work performed } \\
\text { (Creativity assessment, quantity) }\end{array}$ & 3.74 & 3.28 & .215 & 1.976 & .051 \\
\hline PB5 & $\begin{array}{l}\text { Quality of work performed } \\
\text { (Creativity assessment, quality) }\end{array}$ & 4.11 & 3.43 & .378 & 3.211 & $.002 * *$ \\
\hline
\end{tabular}

$* p<.05 ; * * p<.01 ;{ }^{\mathrm{a}}$ Survey questions were adopted from Hye-Jung and Cheolil (2012) 
Table 4. Satisfaction between two classes for English for specific purposes learning

\begin{tabular}{|c|c|c|c|c|c|c|}
\hline \multirow{2}{*}{\multicolumn{2}{|c|}{ Item (rated on a 5-point Likert scale) }} & \multicolumn{2}{|c|}{ Mean } & \multirow{3}{*}{$\begin{array}{c}F \\
.013\end{array}$} & \multirow{3}{*}{$\begin{array}{c}t \\
3.875\end{array}$} & \multirow{3}{*}{$\frac{p \text {-value }}{.001^{* *}}$} \\
\hline & & \multirow{2}{*}{$\frac{1}{4.17}$} & \multirow{2}{*}{$\frac{2}{3.39}$} & & & \\
\hline ESP1 & Broadened my cognition on related ecological knowledge & & & & & \\
\hline ESP2 & Increased my ecological vocabulary & 4.19 & 3.74 & .228 & 2.124 & $.036^{*}$ \\
\hline ESP3 & Improved my related English listening and speaking skills & 3.70 & 3.50 & .279 & .889 & .376 \\
\hline ESP4 & Improved my related English reading and surfing skills & 3.66 & 3.54 & .197 & .611 & .542 \\
\hline ESP5 & Improved my related English writing and translation skills & 3.68 & 3.52 & .145 & .673 & .503 \\
\hline ESP6 & Used technology to promote my motivation to learn about ecology & 3.89 & 3.78 & 6.153 & .492 & .624 \\
\hline
\end{tabular}

In the survey of satisfaction with CPBL, quality of work, collaboration, problem solving, and communication all accounted for higher levels of satisfaction. The practices in this study reveal that CPBL learning mixes themed learning, inquiry learning, and creativity into a new kind of learning pattern. This learning pattern emphasises that learning activities should be problem-oriented. As such, learning theme development and learning environment planning should be done with a focus on the learner (learner-centric) to meet the learner's needs and living situations. Tailoring elements to the learners allows them to form a deep understanding of the themes through the established educational practices and continual problem-solving for issues encountered in the learner's home and the surrounding community (Karau, \& Williams, 1993; Swain, 1998; Williams \& Linn, 2003).

Based on class observation, it is clear that when students had problems with AR design, they first focused on learning how to work with various computer commands and then went on to think about what kind of ecotourism content they could select to better display their ideas regarding ecotourism conservation. This line of thought also covered the audio-visual effect they wanted to include and the AR effects they wanted to share with others. During the design process, the students ran into even more questions and problems. For example, they wondered how they should interact with the tourists, what issues were currently popular for discussion, what other solutions they should try when their AR images were not working, and how to make their AR designs better and more responsive than other groups' designs. Thus, the students had to find ways to decide which ideas were the best out of numerous feasible options, which means they had to rely on their judging capabilities. Because the students had to work together on the shared project, they were willing to cultivate their collaborative skills. They had to be brave enough to share their own thoughts, open enough to listen to others, and patient enough to deal with rejection. Finally, once they found their outcomes were not what they expected, they spent time analysing their work and had to revise their plans in order to achieve their desired results.

In terms of Table 4, most students felt that only the activities of acquiring ecological knowledge and more vocabulary on ecology were special and different from experiences they have had with other courses. Perhaps they did not realise everything that they had actually learned. Chances are, it is more than what they thought. Due to the project, the ESP instructor transformed from being a traditional teacher to a helper and a guide for the students during the learning process. Many students, in fact, were inspired to learn more about ecological conservation.

The learning goal was to give the students training with their English communication skills and strengthen their English abilities, especially their writing (translation) and speaking skills. The students were motivated to express themselves creatively, and the project gave them a chance to display their knowledge of wetland ecology to Chinese people and foreigners in ways that differed from official websites on the topic. They indeed spent time collaborating and negotiating with their peers, problem solving, thinking critically, and keeping open lines of communication (Boss, 2013; Roussos et al., 1999). These are all 21st-century skills that will serve them well and help them further develop their talents (Fadel, 2008).

\subsection{Analysis of Variance for Satisfaction between Three Different English Level Groups}

Table 5 provides the results of the analysis of variance. Student satisfaction for AR, PB, and ESP was tested based on their English level groups to see whether satisfaction levels were significant for any of them. The findings show that satisfaction with AR application and CPBL did not reach significant levels, so the different English level groups had close levels of satisfaction towards the first two parts of the survey. However, satisfaction with ESP learning reached significance, suggesting that the mean of the high English proficiency group is higher than the mean of the low proficiency group. This was further confirmed through a Scheffe test. Therefore, post hoc comparisons were made to decide which statements reached significance between the high English proficiency and low English proficiency groups. 
Table 5. Survey on student satisfaction for augmented reality, comprehensive project-based learning, and English for specific purposes $(N=99)$

\begin{tabular}{ccccccc}
\hline & Score & Mean & SD & $F$ & $p$-value & Scheffe \\
\hline AR & $1^{\text {a }}$ & 3.95 & 0.74 & 1.690 & .190 & --- \\
& $2^{\text {b }}$ & 3.70 & 0.85 & & & \\
& $3^{\text {c }}$ & 3.65 & 0.47 & & & \\
PB & 1 & 3.87 & 0.64 & 2.901 & .060 & -- \\
& 2 & 3.68 & 0.74 & & & \\
& 3 & 3.44 & 0.62 & & & \\
ESP & 1 & 3.95 & 0.64 & 4.289 & $.016^{*}$ & $1>3$ \\
& 2 & 3.79 & 0.74 & & & \\
& 3 & 3.48 & 0.62 & & &
\end{tabular}

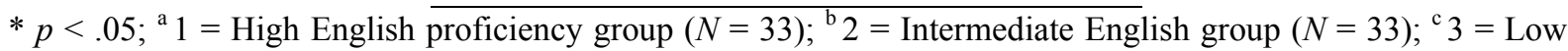
English proficiency group $(N=33)$

Table 6 demonstrates that ESP3 and ESP5 reach significance, which reveals the students felt they improved their English listening, speaking, writing, and translation skills in this study. Compared with the high English proficiency group, it is seen that students in the low proficiency group felt that the project did not improve their learning with regard to the four skills listed above, a point that is worth further discussion.

Table 6. Survey on student satisfaction for English for specific purposes learning $(N=99)$

\begin{tabular}{|c|c|c|c|c|c|c|}
\hline \multirow{2}{*}{\multicolumn{2}{|c|}{ Item (rated on a 5-point Likert scale) }} & \multicolumn{3}{|c|}{ Mean } & \multirow{3}{*}{$\begin{array}{c}F \\
.996\end{array}$} & \multirow{3}{*}{$\frac{p \text {-value }}{.373}$} \\
\hline & & \multirow{2}{*}{$\frac{1^{\mathrm{a}}}{3.85}$} & \multirow{2}{*}{$\frac{2}{3.97}$} & \multirow{2}{*}{$\frac{3}{3.61}$} & & \\
\hline ESP1 & Broadened my cognition on related ecological knowledge & & & & & \\
\hline ESP2 & Increased my ecological vocabulary & 4.18 & 3.94 & 3.82 & .990 & .375 \\
\hline ESP3 & Improved my related English listening and speaking skills & 4.00 & 3.64 & 3.18 & 4.905 & $.009 * *$ \\
\hline ESP4 & Improved my related English reading and surfing skills & 3.73 & 3.79 & 3.30 & 2.663 & .075 \\
\hline ESP5 & Improve my related English writing and translation skills & 3.94 & 3.70 & 3.18 & 3.894 & $.024 *$ \\
\hline ESP6 & Used technology to promote my motivation to learn about ecology & 4.03 & 3.70 & 3.79 & .892 & .413 \\
\hline
\end{tabular}

Being able to acquire English ability comparable to a native speaker is just a learning myth (Kahane, 1992; Kramsch \& Lam, 1999; Prodromou, 1997; Widdowson, 1994). In ESP teaching, teachers are tasked with helping students reduce the number of learning obstacles they face. Teachers can see English skills are important in everyday conversations and at social events, and they prepare language tools to help their students meet future work requirements. For most students in the low proficiency group, their English ability and learning motivation were relatively low compared to their peers in the other groups. It was not easy for them to read English materials and search for the essential pieces of information when they were working on the project. They learned at a slower pace, which also made it hard for them to become engaged with ESP learning through a project.

For many years, general English instructional design has been centred on teachers or textbooks. Students were required to adapt to the teaching style and content as it was presented in their textbooks. Most of the time, the content was arranged based on the teacher's own beliefs and experiences, thus ignoring the students' needs and their capacities. This study serves as a reflection on past practices. CPBL and ESP learning call for high levels of collaboration, intense focus on tasks, communication with peers, and critical thinking. Students involved in such projects should be capable enough in English to do in-depth exploration in terms of the issues or topics at hand. They have to learn how to collect literature, make sound arguments, debate with their peers, and think about how to solve problems by themselves. Although the low proficiency group was not satisfied with the brochure project, the outcome can likely be improved by selecting different topics for the different English level groups. For instance, students in the high English proficiency group could engage in project planning for tours on wetland ecotourism while students in the low proficiency group work on narrowing down what they can do to introduce wildlife and specific plants instead of focusing on the entire park. Students who are struggling need the instructor to offer support and possible solutions. Instructors should spend more time meeting with students in this group to ensure that their learning is on the right track. 


\section{Conclusions and Recommendations}

This study was based on the teaching of English for ecotourism supplemented by CPBL and AR technology to explore how teaching English for ecotourism with AR technology impacts ESP learning and sustainable development. The course was designed to emphasise hands-on experience, full participation, and lively discussion. Students completed in-depth research based on the ecological issues they encountered and combined their knowledge with AR technology to trigger audio-visual content for tourists to watch. Statistical analysis in the form of an independent $t$-test and an analysis of variance was done to examine a student satisfaction survey and the significance of three variables: gender, class, and English proficiency level. The results show that more tourists chose the AR brochures than the general ones, but there was only a small difference with the average correct ratio. Speaking of satisfaction, both the feedback from the foreign language class 1 and the class 2 for CPBL and ESP learning reached significance, and the level of satisfaction for the former class was higher than that of the latter. Moreover, student satisfaction between the three groups with different English proficiency levels revealed that the mean level of satisfaction for all three variables $(\mathrm{AR}=3.95, \mathrm{~PB}=3.87, \mathrm{ESP}=3.95)$ in the high proficiency group was higher than that of the low proficiency group, but only ESP learning reached significance.

Although student acceptance of AR application, CPBL, and ESP learning was not as high as anticipated at the beginning of the project, the teaching approach adopted in this study is completely distinguishable from traditional English teaching models based on in-class teaching. As mentioned in the introduction, the purposes of this study are to increase interest in teaching English for tourism and to emphasise the importance of ecotourism on English for tourism. This study used local environmental resources and features present in wetland parks to lead students to deep learning experiences. This project was aimed at guiding students through an English course while motivating them to care about local environmental issues, learn about the crisis and destruction in Taiwan's wetlands, and examine how humans should act when going out into nature.

From an ESP perspective, English is treated as a tool to cultivate individual communication skills; it is not a language to be mastered on the same standard as native English speakers. The expectation that one can acquire English ability like a native speaker is a learning myth that will only create unnecessary troubles in ESP learning. It is recommended that teachers act as a bridge to connect students to their learning (Ko, 2016), which is aimed at helping them familiarise themselves with using language as a tool and gain professional knowledge. Increased interactions between teachers and students and the presence of two-way communication will offer learners new ideas on how they can be independent knowledge seekers. It is believed this ability to use language effectively will support student learning even outside of and beyond school.

To conclude, this study provides a learning approach that starts with finding problems and ends with possible solutions to them. During the learning process, students searched through literature for useful information on ecotourism and professional English and practised solving problems through critical thinking, communication, and collaboration. The most important result is that the project made students aware of ecotourism education and encouraged them to reflect deeply on the topic of its sustainability. Environmental education is lifelong education. Related issues not only push more people to care about the environment in wetland wildlife refuges but also create opportunities to show people successful cases of wetland rehabilitation. These are all effective ways of supporting sustainable development.

\section{References}

Billinghurst, M., \& Henrysson, A. (2009). Mobile Architectural Augmented Reality. Mixed Reality in Architecture, Design and Construction, 3, 93-104. https://doi.org/10.1007/978-1-4020-9088-2_6

Boss, S. (2013). Projects and Partnerships Build a Stronger Future. Retrieved from https://www.edutopia.org/blog/projects-partnerships-pbl-suzie-boss

Burns, M. (2016). 6 Exciting AR Apps for Student Learning. Retrieved from https://www.edutopia.org/blog/ar-apps-for-student-learning-monica-burns

Chang, R. Q., Liu, Y. L., \& Wu, Z. X. (2015). English for Tourism. New Taipei, Taiwan: Huali Publishing.

Checking form for ecotourism itinerary. (n.d.). Evacuative Information System. Tourism Bureau, M.O.T.C. Republic of China (Taiwan). Retrieved from https://admin.taiwan.net.tw/PageNotFound.aspx

Cheng, K. W. (2018). Let's Go! Have a Nice Trip: Travel English. New Taipei, Taiwan: Cosmos Language Workshop.

Dudley-Evans, T. (1998). An overview of ESP in the 1990s. Paper presented at the Japan Conference on English for Specific Purposes. 
Dudley-Evans, T., \& St. John, M. (1998). Developments in ESP: A Multi-Disciplinary Approach. Cambridge, United Kingdom: Cambridge University Press.

Fadel, C. (2008). 21st Century Skills: How can you prepare students for the new Global Economy? Global Lead, Education Cisco System, Inc. OECD/CERI, Paris. Retrieved from https://www.oecd.org/site/educeri21st/40756908.pdf

Kahane, H. (1992). American English: From a colonial standard to prestige language. In B. B. Kachru (Ed.), The Other Tongue: English across Cultures. Urbana, United States: University Illinois Press. https://doi.org/10.1017/s0272263100004939

Karau, S. J., \& Williams, K. D. (1993). Social Loafing: A Meta-analytic Review and Theoretical Integration. Journal of Personality and Social Psychology, 65(4), 681-706. https://doi.org/10.1037/0022-3514.65.4.681

Ko, H. C. (2016). An approach to the design of digital classic Chinese article learning system for undergraduate students using "the homecoming" as an example. Multimed Tools Appl, 75(16), 9991-10012. https://doi.org/10.1007/s11042-015-3126-z

Kramsch, C., \& Lam, W. S. E. (1999). Textual identities: The importance of being non-native. In G. Braine (Ed.), Non-Native Educators in English Language Teaching. Mahwah, United States: Erlbaum. https://doi.org/10.4324/9781315045368

Lee, H. J., \& Lim, C. (2012). Peer Evaluation in Blended Team Project-Based Learning: What Do Students Find Important? Journal of Educational Technology \& Society, 15(4), 214-224.

Lee, S. H., Choi, J., \& Park, J. (2009). Interactive E-Learning System Using Pattern Recognition and Augmented Reality. IEEE Transactions on Consumer Electronics, 55(2), 883-890. https://doi.org/10.1109/tce.2009.5174470

Live ABC (Eds.). (2014). The Smart Traveler's Guide to English. Taipei, Taiwan: Hebron Publishing.

Oxford English Dictionary Second Edition on CD-ROM, Version 4.0, draft entries December 2001, Oxford University Press 2009. Citing: ' 1973 Ecol. Interpretative Map, Ottawa-North Bay (Canad. Forestry Service) (heading) Ecotour of the Trans-Canada Highway, Ottawa-North Bay', and '1982 (title) Ecological tourism (ecotourism): A new viewpoint (U.N. F.A.O. \& Econ. Comm. for Europe)'.

Prodromou, L. (1997). Global English and the Octopus. IATEFL Newsletter, 137, 18-22.

Robinson, P. (1991). ESP Today: A Practitioner's Guide. Hemel Hempstead, United Kingdom: Prentice Hall.

Roussos, M., Johnson, A., Moher, T., Leigh, J., Vasilakis, C., \& Barnes, C. (1999). Learning and Building Together in an Immersive Virtual World. Presence Journal, 8(3), 247-263. https://doi.org/10.1162/105474699566215

Swain, M. (1998). Focus on form through conscious reflection. In C. Doughety, \& J. Williams (Eds.), Focus on Form in Classroom Second Language Acquisition. Cambridge, United Kingdom: Cambridge University Press.

The International Ecotourism Society. (n.d.). What Is Ecotourism? Retrieved from https://ecotourism.org/what-is-ecotourism/

Weaver, D. B. (2001). The Encyclopedia of Ecotourism. New York, USA: Cabi Publishing.

Widdowson, H. (1994). The Ownership of English. TESOL Quarterly, 28, 377-389.

Widdowson, H. G. (1983). Learning Purpose and Language Use. Oxford, United Kingdom: Oxford University Press.

Williams, M., \& Linn, M. (2003). WISE Inquiry in Fifth Grade Biology. Research in Science Education, 32(4), 415-436. https://doi.org/10.1023/A:1022452719316

Zhou, F., Duh, H. L., \& Billinghurst, M. (2008). Trends in Augmented Reality Tracking, Interaction and Display: A Review of Ten Years in ISMAR. Mixed and Augmented Reality, ISMAR 7th IEE/ACM International Symposium (pp. 193-202). Cambridge: IEEE. https://doi.org/10.1109/ismar.2008.4637362 


\section{Notes}

Note 1. Image of AR master 1.

Available Online: https://photo.xuite.net/zhongheland/15163343/1174.jpg (accessed on 25 June, 2018).

Note 2. Image of AR master 2.

Available Online: http://www.clipartpanda.com/clipart_images/genius-boy-coming-up-with-a-68198651 (accessed on 25 June, 2018).

\section{Copyrights}

Copyright for this article is retained by the author(s), with first publication rights granted to the journal.

This is an open-access article distributed under the terms and conditions of the Creative Commons Attribution license (http://creativecommons.org/licenses/by/4.0/). 